\title{
Composição físico-química e aceitação sensorial da inflorescência de gengibre orgânico (Zingiber officinale Roscoe)
}

\author{
Physicochemical composition and sensory acceptance of organic ginger inflorescences (Zingiber officinale Roscoe)
}

\author{
Isadora Balsini $\mathrm{LUCIO}^{1 *}$, Renato João Sossela de FREITAS², Nina WASZCZYNSKYJ ${ }^{2}$
}

\begin{abstract}
Resumo
Em Morretes - PR, Brasil, existe uma demanda da utilização integral da planta do gengibre (rizoma e parte aérea), portanto, o conhecimento da composição química e a avaliação sensorial de inflorescência de gengibre tornam-se importantes. O objetivo do presente trabalho foi analisar a composição físico-química e aceitação sensorial de inflorescência de gengibre orgânico. Com a inflorescência de gengibre orgânico, foram elaborados chá, suco e salada e foi verificada sua aceitação com utilização de escala hedônica. As inflorescências de gengibre orgânico, verde e rosada, respectivamente, apresentaram 93,23 e 94,54\% de umidade, 0,83 e 0,81\% de cinzas, 17,98 e 12,36\% de proteínas, 3,90 e 3,81\% de lipídios, 19,22 e 23,99\% de fibra bruta e 58,07 e 59,03\% de carboidratos. Com o amadurecimento, as inflorescências de gengibre têm o seu teor de proteínas diminuído e o teor de fibras aumentado. Para o consumo das inflorescências, indica-se sua utilização para o preparo de chá, produto que apresentou mais de $80 \%$ de aceitação pelos julgadores.

Palavras-chave: chá; suco; salada; composição química; utilização integral do gengibre; frequência de aceitação.
\end{abstract}

\begin{abstract}
In the city of Morretes - PR, Brazil, there is a demand of the use of the full plant of ginger (rhizome and air part); thus, the knowledge of the chemical composition and sensory evaluation of ginger inflorescences have become important. The objective of this study was to analyze the physicochemical composition and sensory acceptance of the organic ginger inflorescence. Tea, juice, and salad were prepared with the inflorescences of organic ginger and their acceptance was verified with the use of the hedonic scale. The inflorescences of organic ginger (green and mature, respectively), presented 93.23 and $94.54 \%$ of moisture, 0.83 and $0.81 \%$ of ash, 17.98 and $12.36 \%$ of protein, 3.90 and $3.81 \%$ of fat, 19.22 and $23.99 \%$ of crude fiber, and 58.07 and $59.03 \%$ of carbohydrates. The content of protein decreased with maturity and the fiber content increased. For the consumption of inflorescences, it is recommended the use of tea, a product that presented more than $80 \%$ of acceptance by the panelists.
\end{abstract}

Keywords: tea; juice; salad; chemical composition; full use of ginger; level of acceptance.

\section{Introdução}

O gengibre (Zingiber officinale Roscoe) é uma planta herbácea, composta por rizoma e parte aérea. O rizoma é formado por ramificações horizontais (dedos), palmadas, carnosas, e pouco fibrosas. É a parte comercial da planta (GONZAGA; RODRIGUES, 2001; SILVESTRINI et al., 1996).

A parte aérea é formada por caules articulados eretos, de 30 a $150 \mathrm{~cm}$ de altura, com folhas grandes lanceoladas, com ramificações situadas num mesmo plano, distintamente dispostas, com larga bainha na base que envolve o caule. $\mathrm{O}$ gengibre possui também inflorescências que são sustentadas por caules eretos, com cerca de $20 \mathrm{~cm}$ de altura, sendo a inflorescência terminal uma espiga ovoide composta de brácteas que protegem as flores (SILVESTRINI et al., 1996). As flores são verde-amareladas, hermafroditas, dispostas em espigas ovoides, no ápice dos pedúnculos, com brácteas florais esverdeadas, as margens amarelas, ponteadas de roxo. O fruto é uma cápsula triocular que se fende em três válvulas; as sementes são azuladas e contêm um albúmen carnoso (GONZAGA; RODRIGUES, 2001).

De acordo com Purseglove et al. (1997), a legislação vigente e os dados de comercialização informam que somente o rizoma in natura é ofertado ao mercado consumidor, como gengibre fresco, em conserva, cristalizado e seco.

O litoral paranaense, especialmente o município de Morretes - PR, é o principal produtor de gengibre do Brasil (ELPO; NEGRELLE; RÜCKER, 2008). Portanto, existe uma demanda da utilização integral da planta do gengibre. Muitos produtores já estão trabalhando com o cultivo de gengibre orgânico, o que possibilitaria a utilização da inflorescência como alimento - a exemplo de outras inflorescências comestíveis, como o brócolis e a couve-flor.

\footnotetext{
Recebido para publicação em 30/5/2008

Aceito para publicação em 8/7/2009 (003505)

'Programa de Pós-graduação em Tecnologia de Alimentos, Universidade Federal do Paraná - UFPR,Universidade Federal do Recôncavo da Bahia - UFRB,

CP 78, CEP 44570-000, Santo Antônio de Jesus - BA, Brasil, E-mail: ibalsini@uol.com.br

${ }^{2}$ Programa de Pós-graduação em Tecnologia de Alimentos, Universidade Federal do Paraná - UFPR, Curitiba - PR, Brasil

${ }^{*}$ A quem a correspondência deve ser enviada
} 
No Brasil, existe um grande potencial de novos produtos alimentícios que vêm sendo pesquisados. Alimentos nem sempre convencionais, mas de grande importância do ponto de vista nutricional e que poderiam ser mais bem explorados.

O conhecimento da composição química e a avaliação sensorial de inflorescência de gengibre são essenciais para poder avaliar a aceitação desse produto, valorizando o uso da inflorescência de gengibre na alimentação humana.

O consumidor é um provador sensorial em potencial, podendo decidir o que irá consumir, o que levará para sua residência e como utilizará o produto (processado ou in natura). Os fatores determinantes para a aceitação dos produtos de origem alimentícia são a aparência, o aroma, o sabor, a textura e a embalagem. A análise sensorial atua de forma sincronizada com esses atributos sensoriais, buscando atender às necessidades dos consumidores e dos produtores (PEDRÃO, 1999; TEIXEIRA, 2007).

O objetivo do presente trabalho foi analisar a composição físico-química e a aceitação sensorial da inflorescência de gengibre orgânico, nas formas de chá, suco e salada.

\section{Material e métodos}

\subsection{Colheita e preparo das amostras}

As amostras utilizadas no presente estudo foram provenientes de uma cultura de gengibre orgânico, certificada pelo IBD (Instituto Biodinâmico) no litoral paranaense, no município de Morretes - PR, Brasil.

As inflorescências foram colhidas em dois estágios de acordo com a cor apresentada por elas. Considerou-se inflorescência "verde" a que apresentava pétalas com tonalidade verde e amarelada; e inflorescência "rosada", a que apresentava coloração rosa-avermelhado. No mesmo dia da colheita, as inflorescências foram lavadas em água corrente, deixadas de molho por 15 minutos em solução de água com água sanitária (1 colher de sopa de água sanitária para $1 \mathrm{~L}$ de água) e deixadas para secar na sombra. Foram armazenadas congeladas, sendo embaladas individualmente com filme de PVC, identificadas, empacotadas com papel jornal, acondicionadas em caixa de papelão e estocadas em freezer a $-18^{\circ} \mathrm{C}$.

Foram analisadas as inflorescências de gengibre (Zingiber officinale Roscoe), plantadas em outubro de 2005 e colhidas entre março e maio de 2006, sendo, em média, 15 inflorescências com peso médio de $10 \mathrm{~g}$ para cada amostra.

Para a realização das análises físico-químicas, as inflorescências foram descongeladas em temperatura ambiente $\left(25 \pm 1^{\circ} \mathrm{C}\right)$ e cortadas em pequenos cilindros com $0,5 \mathrm{~mm}$ de comprimento para melhor homogeneização.

O chá, o suco e a salada de inflorescência de gengibre foram elaborados respeitando a característica de inflorescência in natura, isto é, não foi acrescentado aos produtos nenhum outro alimento com nutrientes ou sabores que pudessem interferir na avaliação final das preparações.

\section{Chá de inflorescência de gengibre}

As inflorescências de gengibre foram picadas em cilindros pequenos com 0,5 mm de comprimento e, então, secos em estufa a $70^{\circ} \mathrm{C}$ por aproximadamente 24 horas, até peso constante e, em seguida, trituradas em liquidificador.

A infusão foi realizada de acordo com o padrão encontrado em chás industrializados (DR. OETKER..., 2008). Para cada grama de produto seco, foram acrescentados $150 \mathrm{~mL}$ de água mineral fervente $\left(97 \pm 1^{\circ} \mathrm{C}\right)$ e mantido em infusão durante 3 minutos, até surgimento de cor, sabor e liberação dos compostos voláteis.

O chá então foi filtrado em peneira (abertura $2 \times 2 \mathrm{~mm}$ ) e em tecido de algodão esterilizado para retenção dos resíduos sólidos.

As amostras de chá $(30 \mathrm{~mL})$, foram servidas aos julgadores em temperatura de $45 \pm 1^{\circ} \mathrm{C}$, em copos térmicos descartáveis de polipropileno atóxico para bebidas quentes, com capacidade de $100 \mathrm{~mL}$.

\section{Suco de inflorescência de gengibre}

Foram utilizadas inflorescências de gengibre in natura cruas e descongeladas, trituradas em liquidificador por 3 minutos com água mineral na proporção de $1 / 3$ de inflorescências. Em seguida, o suco foi coado em peneira (abertura $2 \times 2 \mathrm{~mm}$ ).

As amostras $(100 \mathrm{~mL})$ foram servidas aos julgadores em temperatura de $12 \pm 1{ }^{\circ} \mathrm{C}$, em copos do tipo cristal descartável para cerveja, suco e/ou água, de poliestireno atóxico, capacidade $300 \mathrm{~mL}$.

\section{Salada de inflorescência de gengibre}

As inflorescências de gengibre in natura cruas e descongeladas foram levadas para cocção em água em ebulição $\left(97 \pm 1^{\circ} \mathrm{C}\right)$ por 12 minutos. Esse tempo foi necessário para que as fibras fossem abrandadas, permitindo a mastigação, sem formação de massa compacta na cavidade bucal, o que dificultaria a deglutição. Após a cocção, a água foi removida e as inflorescências de gengibre picadas em pedaços pequenos.

A salada das inflorescências do gengibre foi servida aos julgadores em temperatura de $12 \pm 1{ }^{\circ} \mathrm{C}$, em pratos tipo cristal, descartáveis, não tóxicos, de $150 \mathrm{~mm}$ de diâmetro, acompanhados de garfo e faca (talheres plásticos). Cada julgador recebeu $20 \mathrm{~g}$ de salada.

\subsection{Metodologia analítica}

Todas as análises físico-químicas foram realizadas de acordo com a metodologia descrita pela Association of Official Analytical Chemists (ASSOCIATION..., 2000), em triplicatas.

Determinou-se a umidade em estufa (Marconi MA 035) com circulação forçada de ar na temperatura de $105^{\circ} \mathrm{C}$, até peso constante. $\mathrm{O}$ teor de cinzas foi determinado através da carbonização em fogareiro e depois incineração em mufla (Quimis) a $550-600^{\circ} \mathrm{C}$ durante cinco horas. 
As proteínas foram determinadas pelo nitrogênio total, utilizando-se o método de Kjeldahl (macro-Kjeldahl Prodicil) e o fator 6,25 para conversão em proteína, conforme o método 955.04C da AOAC (ASSOCIATION..., 2000). Determinou-se o extrato etéreo (lipídios) por extração com éter etílico, durante cinco horas, em extrator de Soxhlet (Prodicil), conforme método 920.39C da AOAC (ASSOCIATION..., 2000). Para determinação da fibra bruta, foi utilizado método gravimétrico consistindo de digestão (ácida e básica), secagem do resíduo e pesagem. Os carboidratos totais foram calculados por diferença [100 g - total g (proteína, lipídios, umidade, cinzas, fibra bruta)] (UNIVERSIDADE..., 2007).

\subsection{Análise sensorial}

A avaliação sensorial foi realizada na Universidade Federal do Recôncavo da Bahia - UFRB, Centro de Ciências da Saúde (CCS), em Santo Antônio de Jesus - BA, no Laboratório de Técnica Dietética, com uma equipe de 39 julgadores treinados. A equipe foi composta por professores, alunos e funcionários da Universidade acima mencionada.

Para o recrutamento dos candidatos, foram afixados nos murais do CCS/UFRB convites para toda a comunidade universitária participar de uma análise sensorial de inflorescência de gengibre. As pessoas interessadas preencheram então um questionário para verificar a disponibilidade dos candidatos e se seus hábitos alimentares se encaixavam no perfil da pesquisa. Todas essas etapas ocorreram entre os meses de outubro/2007 a janeiro/2008, com duas a três sessões semanais.

Conforme descrito em Lucio, Freitas e Waszczynskyj (2008), quarenta e seis candidatos demonstraram interesse em participar da análise sensorial das inflorescências de gengibre, preencheram o questionário, foram entrevistados e participaram do minicurso sobre análise sensorial. Após o minicurso, dois candidatos decidiram abandonar o grupo inicial. Por conseguinte, 44 candidatos participaram do treinamento por meio de testes triangulares e familiarização com as amostras de inflorescência de gengibre. Completadas essas etapas, 39 candidatos foram considerados julgadores treinados, conforme a análise dos resultados das sessões de teste triangular realizadas e analisados por meio da Análise Sequencial de Wald.

Para os testes sensoriais, optou-se trabalhar com a inflorescência verde de gengibre orgânico, devido a seu valor nutricional e maior facilidade de armazenamento.

Com os julgadores selecionados e treinados, o chá, o suco e a salada elaborados com a inflorescência de gengibre foram analisados utilizando o teste de aceitação. Para a avaliação global das amostras, os julgadores utilizaram a escala hedônica de 9 pontos, ancorada nas extremidades de "gostei muitíssimo" (9) a “desgostei muitíssimo” (1) ((ASSOCIAÇÃO..., 1998; QUEIROZ; TREPTOW, 2006; MEILGAARD; CIVILLE; CARR, 1991).

\subsection{Análise estatística dos dados}

Os dados obtidos foram submetidos à análise de variância, teste $\mathrm{F}$ e Teste de Tukey para verificar a ocorrência de diferenças estatisticamente significativas $(\mathrm{p}<0,01$ e $\mathrm{p}<0,05)$ entre as amostras (MONTGOMERY, 2000; PIMENTEL-GOMES, 1991).
Os cálculos foram efetuados utilizando o programa estatístico SAS (SAS, 1992).

\section{Resultados e discussão}

Não existe nenhum relato de análise da composição química centesimal de inflorescências de gengibre orgânico na literatura. Os valores encontrados neste trabalho são apresentados na Tabela 1.

Segundo Magalhães et al. (1997), a composição química do rizoma de gengibre pode variar de 80 a $90 \%$ para umidade, 5 a $13 \%$ de proteínas, 3 a $8 \%$ de lipídios, 5 a $11 \%$ de fibra bruta e 4 a $8 \%$ de cinzas. Ao comparar os valores encontrados para as inflorescências de gengibre (Tabela 1), observa-se que as inflorescências possuem maior teor de umidade, proteínas e fibra bruta, e menores quantidades de cinzas sem diferirem na quantidade de lipídios dos rizomas.

Quando comparado com outras inflorescências utilizadas na alimentação, como o brócolis e a couve-flor, as inflorescências de gengibre verde (Tabela 1) possuem 6 vezes mais proteínas e 6,4 vezes mais fibras do que o brócolis e, 9 vezes mais proteínas e 9,8 vezes mais fibras do que a couve-flor. A inflorescência de gengibre rosada (Tabela 1 ) possui 4,1 vezes mais proteínas e 7,9 vezes mais fibras do que o brócolis e, 6,2 vezes mais proteínas e 12 vezes mais fibras do que a couve-flor. Estes dados são baseados na composição apresentada por Philippi (2002), em que o brócolis possui 2,99 g. $100 \mathrm{~g}^{-1}$ de proteínas e $3,00 \mathrm{~g} .100 \mathrm{~g}^{-1}$ de fibras e a couve-flor possui $1,99 \mathrm{~g} .100 \mathrm{~g}^{-1}$ de proteínas e 1,95 g. $100 \mathrm{~g}^{-1}$ de fibras.

Não houve diferença estatística nas quantidades de umidade, cinzas, lipídios e carboidratos após o amadurecimento das inflorescências de gengibre orgânico. Os componentes que merecem destaque na composição química das inflorescências de gengibre orgânico verde e rosada (Tabela 1) são as proteínas e as fibras.

O teor de proteína e fibras encontrado nas inflorescências de gengibre se aproxima das leguminosas, consideradas entre os alimentos de origem vegetal, as mais completas em aminoácidos essenciais, sendo deficientes apenas em metionina. $\mathrm{O}$ feijão e o grão-de-bico, por exemplo, possuem respectivamente 17,30 e $21,20 \%$ de proteínas e 24,0 e $12,4 \%$ de fibras (NÚCLEO..., 2006).

A quantidade de proteína presente na inflorescência verde de gengibre orgânico $(17,98 \%)$, apesar de possuir baixo valor biológico, apresenta um valor próximo ao encontrado em

Tabela 1. Composição química de inflorescência de gengibre orgânico.

\begin{tabular}{|c|c|c|}
\hline \multirow[t]{3}{*}{ Determinações $\left(\mathrm{g} .100 \mathrm{~g}^{-1}\right)$} & \multicolumn{2}{|c|}{ Inflorescência de gengibre orgânico } \\
\hline & Verde & Rosada \\
\hline & Média \pm DP $n=3$ & Média \pm DP $n=3$ \\
\hline Umidade & $93,23 \pm 0,22^{\mathrm{ns}}$ & $94,54 \pm 0,32^{\mathrm{ns}}$ \\
\hline Cinzas $^{1}$ & $0,83 \pm 0,08^{\mathrm{ns}}$ & $0,81 \pm 0,03^{\mathrm{ns}}$ \\
\hline Proteína $^{1}$ & $17,98 \pm 0,91^{\mathrm{a}}$ & $12,36 \pm 0,60^{\mathrm{b}}$ \\
\hline Lipídios $^{1}$ & $3,90 \pm 0,23^{\mathrm{ns}}$ & $3,81 \pm 0,15^{\mathrm{ns}}$ \\
\hline Fibra Bruta ${ }^{1}$ & $19,22 \pm 0,28^{\mathrm{b}}$ & $23,99 \pm 0,37^{\mathrm{a}}$ \\
\hline Carboidratos $^{1}$ & $58,07 \pm 0,57^{\mathrm{ns}}$ & $59,03 \pm 0,45^{\mathrm{ns}}$ \\
\hline
\end{tabular}

Médias seguidas na mesma linha por letras iguais não diferem estatisticamente no nível de $1 \%(\mathrm{p} \leq 0,01) ; \mathrm{ns}=$ não significativo; os resultados correspondem à média das amostras,

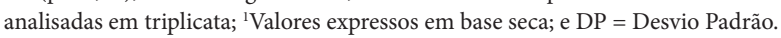


alimentos de origem animal, que são considerados fontes de proteína, como: peixe linguado $(18,80 \%)$, queijo tipo cottage $(14,50 \%)$, carne de coelho $(14,42 \%)$, coxa de frango $(17,30 \%)$, ovo (12,40\%), e leite em pó (11,40\%) (PHILIPPI, 2002).

Nota-se que, com o amadurecimento, existe um decréscimo na quantidade de proteínas e um aumento na quantidade de fibras, estatisticamente diferentes em nível de 1\% de significância (Tabela 1). Essa observação corrobora com o encontrado por Aguiar, Vasquez e Silva (2000), que constatou, ao analisar a composição químico-bromatológica de capim furachão, uma diminuição drástica no teor proteico e aumento do teor de fibra com o amadurecimento.

Esse aumento do teor de fibras e diminuição do teor proteico decorrente do amadurecimento das inflorescências pode ser explicado pelo fato de que, com o amadurecimento das plantas, ocorre uma diminuição do conteúdo celular e consequente elevação dos constituintes da parede celular (AGUIAR; VASQUEZ; SILVA, 2000).

Alimentos de origem vegetal, como o palmito, são apreciados por sua textura tenra, baixa fibrosidade, sabor suave e agradável (YOKOMIZO; FARIA NETO, 2003). A exemplo desse, a inflorescência de gengibre verde, menos fibrosa do que a rosada, deve ser o objeto de estudo para utilização na alimentação humana.

No teste de aceitação, as amostras de chá, suco e salada de inflorescência de gengibre obtiveram médias 7,41, 7,00 e 6,59, respectivamente, e não diferem estatisticamente no nível de $5 \%(\mathrm{p} \leq 0,05)$.

A Figura 1 apresenta os resultados da análise sensorial. Os alimentos elaborados foram considerados aceitos pelos julgadores ao receberem as notas 7 (gostei regularmente), 8 (gostei muito) e 9 (gostei muitíssimo) e a frequência destas notas ser de no mínimo $70 \%$.

Observa-se (Figura 1) que para o chá de inflorescência de gengibre a somatória da frequência das notas atribuídas 7,8 e 9 atingem $82,1 \%$; para o suco $69,2 \%$; e para a salada $59,0 \%$.

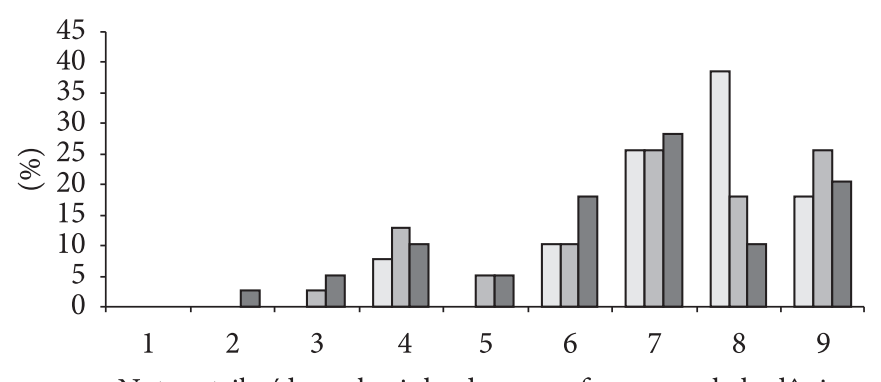

Notas atribuídas pelos julgadores conforme escala hedônica

$$
\square \text { Chá } \square \text { Suco } \square \text { Salada }
$$

Figura 1. Histograma de distribuição de notas para o teste de aceitação do chá, suco e salada elaborados com a inflorescência verde de gengibre orgânico.
Com isso, verifica-se que o chá de inflorescências de gengibre, apresenta uma maior concentração de notas entre 7 e 9, sendo a única elaboração aceita pelos julgadores.

Além disto, conforme Lucio, Freitas e Waszczynskyj (2008), o chá de inflorescência de gengibre apresenta uma atitude de consumo média de $79,5 \%$, e é descrito como um alimento agradável.

\section{Conclusões}

Com o amadurecimento, as inflorescências de gengibre têm o seu teor de proteínas diminuído e o teor de fibras aumentado.

As inflorescências de gengibre podem ser mais uma alternativa de um alimento nutritivo disponível no mercado para os consumidores. É interessante sua utilização como alimento rico em proteínas e fibras, preferencialmente com inflorescências de gengibre verdes.

Dentre as elaborações formuladas com a inflorescência de gengibre e avaliadas, indica-se sua utilização para o preparo de chá, produto que apresentou mais de $80 \%$ de aceitação pelos julgadores.

\section{Referências bibliográficas}

AGUIAR, R. S.; VASQUEZ, H. M.; SILVA, J. F. C. Produção e composição químico-bromatológica do capim-furachão (Panicum repens L.) sob adubação e diferentes idades de corte. Revista Brasileira de Zootecnia, v. 29, n. 2, p. 325-333, 2000.

ASSOCIAÇÃO BRASILEIRA DE NORMAS TÉCNICAS - ABNT. NBR 14141. Escalas utilizadas em análise sensorial de alimentos e bebidas. Rio de Janeiro, 1998.

ASSOCIATION OF OFFICIAL ANALYTICAL CHEMISTS - AOAC. Official methods of analysis of AOAC International. $17^{\text {th }} \mathrm{ed}$. Gaithersburg, 2000. v. 1-2.

DR. OETKER do Brasil. Produtos - chás - chás de ervas. Disponível em: <http://www.oetker.com.br/?actA=2111\&produtoID=113>. Acesso em: 21 mar. 2008.

ELPO, E. R. S.; NEGRELLE, R. R. B.; RÜCKER, N. G. A. Produção de gengibre no município de Morretes, PR. Scientia Agraria, v. 9, n. 2, p. 211-217, 2008.

GONZAGA, D. S. O. M.; RODRIGUES, V. G. Gengibre - Zingiber officinale Roscoe. [S.1.]: EMBRAPA, dez. 2001. (Série Plantas Medicinais, Folder 12).

LUCIO, I. B.; FREITAS, R. J. S.; WASZCZYNSKYJ, N. Perfil de atributos e atitude de consumo de infusão, suco e salada elaborados com a inflorescência verde de gengibre orgânico (Zingiber officinale Roscoe). Alimentação Humana - Revista da SPCNA, v. 14, n. 1, p. 28-40, 2008.

MAGALHÃES, T. M. et al. Gengibre (Zingiber officinale Roscoe) Brasileiro: aspectos gerais, óleo essencial e oleoresina. Parte 1 - Aspectos gerais, óleo essencial. Ciência e Tecnologia dos Alimentos, v. 17, n. 1, p. 64-69, jan.-abr. 1997.

MEILGAARD, M.; CIVILLE, G. V.; CARR, B. T. Sensory Evaluation Techniques. 2. ed. Boca Raton: CRC Press, 1991.

MONTGOMERY, D. C. Design and analysis of experiments. New York: Wiley, 2000. 
NÚCLEO DE ESTUDOS E PESQUISAS EM ALIMENTAÇÃO - NEPA (UNICAMP). Tabela brasileira de composição de alimentos. Versão II. 2. ed. Campinas, 2006.

PEDRÃO, M. R. Análise sensorial e sua importância na pesquisa de alimentos. Ciência e Biologia da Saúde, v. 1, n. 1, p. 85-89, out. 1999.

PHILIPPI, S. T. Tabela de Composição de Alimentos: suporte para decisão nutricional. 2. ed. São Paulo: Coronário, 2002.

PIMENTEL-GOMES, F. Curso de estatística experimental. 13. ed. São Paulo: Nobel, 1991.

PURSEGLOVE, J. W. et al. Gengibre (Zingiber officinale Roscoe) Brasileiro: aspectos gerais, óleo essencial e oleoresina. Parte 1 - Aspectos gerais, óleo essencial. Ciência e Tecnologia dos Alimentos, v. 17, n. 1, p. 64-69, jan.-abr. 1997.
QUEIROZ, M. I.; TREPTOW, R. O. Análise sensorial para a avaliação da qualidade dos alimentos. Rio Grande: Editora da FURG, 2006.

SAS STATISTICAL ANALYSIS SYSTEM. Versão 6.08. Cary, N.C.: The SAS Institute, 1992.

SILVESTRINI, A. et al. A cultura do gengibre. Curitiba: EMATER/ PR, 1996.

TEIXEIRA, K. R. Fundação Centro Tecnológico de Minas Gerais CETEC. Resposta Técnica - Análise Sensorial, 20 maio 2007.

UNIVERSIDADE DE SÃO PAULO - USP. Tabela brasileira de composição de alimentos: projeto integrado de composição de alimentos. Disponível em: <http://www.fcf.usp.br/tabela >. Acesso em: 13 fev. 2007.

YOKOMIZO, G. K.; FARIA NETO, J. T. de. Caracterização fenotípica e genotípica de progênies de pupunheira para palmito. Pesquisa Agropecuária Brasileira, v. 38, n. 1, p. 67-72, jan. 2003. 